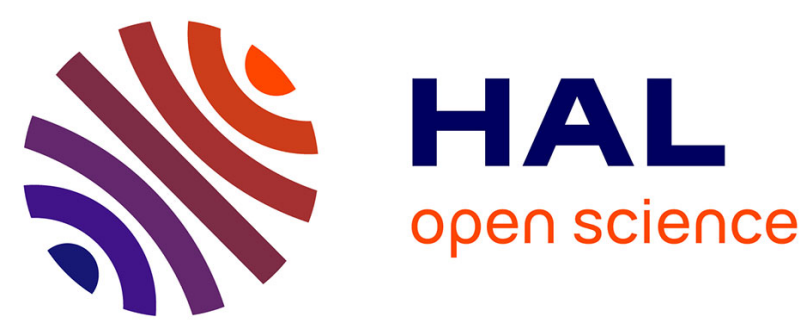

\title{
Mechanical behaviour and temperature measurement during dynamic deformation on split Hopkinson bar of 304L stainless steel and 5754 aluminium alloy
}

\author{
C. Jovic, D. Wagner, P. Hervé, Gérard Gary, L. Lazarotto
}

\section{- To cite this version:}

C. Jovic, D. Wagner, P. Hervé, Gérard Gary, L. Lazarotto. Mechanical behaviour and temperature measurement during dynamic deformation on split Hopkinson bar of 304L stainless steel and 5754 aluminium alloy. Journal de Physique IV Proceedings, 2006, EURODYMAT 2006 - 8th International Conference on Mechanical and Physical Behaviour of Materials under Dynamic Loading, 134, pp.12791285. 10.1051/jp4:2006134194 . hal-00119964

\author{
HAL Id: hal-00119964 \\ https://hal.science/hal-00119964
}

Submitted on 28 Aug 2018

HAL is a multi-disciplinary open access archive for the deposit and dissemination of scientific research documents, whether they are published or not. The documents may come from teaching and research institutions in France or abroad, or from public or private research centers.
L'archive ouverte pluridisciplinaire HAL, est destinée au dépôt et à la diffusion de documents scientifiques de niveau recherche, publiés ou non, émanant des établissements d'enseignement et de recherche français ou étrangers, des laboratoires publics ou privés. 


\section{Mechanical behaviour and temperature measurement during dynamic deformation on split Hopkinson bar of 304L stainless steel and $\mathbf{5 7 5 4}$ aluminium alloy}

C. Jovic ${ }^{1,2}$, D. Wagner ${ }^{2}$, P. Herve ${ }^{2}$, G. Gary ${ }^{3}$ and L. Lazzarotto ${ }^{1}$

${ }^{1}$ CETIM, 7 rue de la Presse, BP. 802, 42952 Saint Étienne, France

2 Laboratoire LEEE, Université Paris X, 92410 Ville d'Avray, France

${ }^{3}$ LMS, École Polytechnique, 91128 Palaiseau Cedex, France

\section{INTRODUCTION}

A new type of machine for materials working has appeared for a few years. These machines are able to combine important speeds, a rate and a lifetime, associated to potential positive effects on the forged products properties. The platform "forge and simulation" of CETIM initiated - in collaboration with various laboratories - a study on cold working at high speed of massive products, as they wished to study the possibilities of application of this press to industrial circle. The high strain rates can generate two contradictory physical phenomena. On the one hand, the process is called adiabatic when - during the deformation of a material - the generate heat is not evacuated to the rest of the system. It creates a heating which can soften the material and decrease the effort necessary for forming it. On the other hand during a high speed loading, an increase of yield stress of the material can be observed at high strain rate, as well as a hardening of the material and an increase of the effort necessary for forming it. At last, another phenomenon can sometimes be observed. It is known as adiabatic shearing. When it occurs, it generates the rupture of the pieces $[1,2]$.

Data quoted in literature tallies with the fact that the behaviour in dynamics varies from tests into quasi-statics - for the majority of the materials - by a rise in the yield stress and in the flow stress $[3,4]$. The mechanical behaviour of the selected materials (304L stainless steel and 5754 aluminium alloy) were determined at variable speed rates on Split Hopkinson Bar. Temperatures were determined on the surface of sample when tests carried out on Split Hopkinson bar by optical pyrometry were executed. Taylor-Quinney coefficient corresponding to the plastic fraction of work converted into heat was also determined. 


\section{APPARATUS PRESENTATION}

\subsection{Split Hopkinson bar}

The mechanical behaviour of studied materials (5754 aluminium alloy and 304L stainless steel) was carried out on Split Hopkinson Bar [5]. We used Split Hopkinson Bar in compression (figure 1). The studied sample can be deformed at high strain rates on a state of uniaxial stresses. The strains, stresses and strain rates can be calculated by using the properties of elastic waves propagation in the bars. This technic consists in intercalating the sample to study between two identical bars. The material used in the design of the bars must have a higher yield stress than the material studied. A strike bar is propelled by a compressed-air gun. It comes to impact the incident bar at a variable speed which can be controlled by the user. The induced shock will produce a longitudinal elastic compression wave which is propagated in the entering bar. Part of this wave is transmitted to the sample first and then to the transmitter bar. The other part of the wave is thrown back to the bars interface. Two strain gages permit to measure the deformations generated by the incident, transmitted and reflected waves. The behaviour of the sample can be calculated by gauges signals (Figure 1 and figure 2).

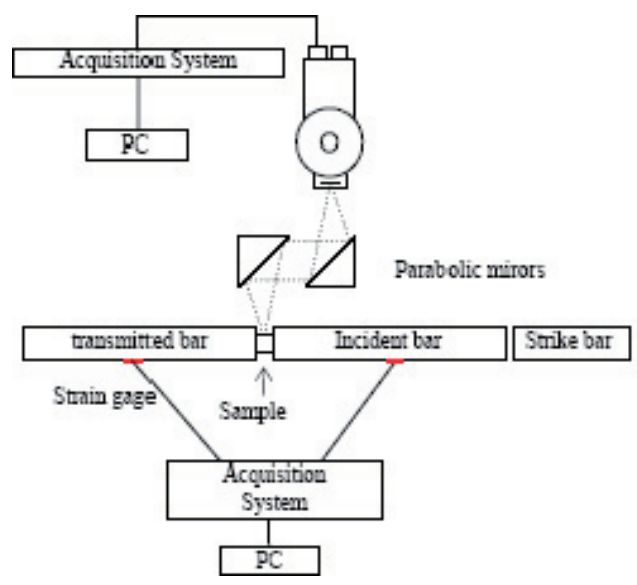

a) Schema of the apparatus

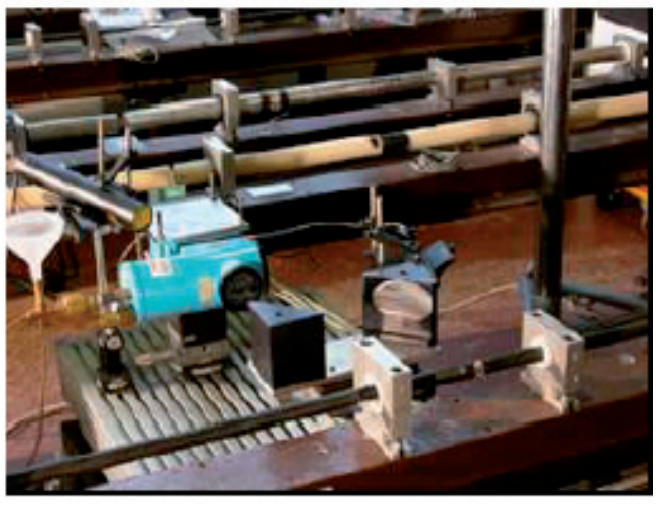

b) Photography of the apparatus

Figure 1. System of temperatures measurement for split Hopkinson bar.

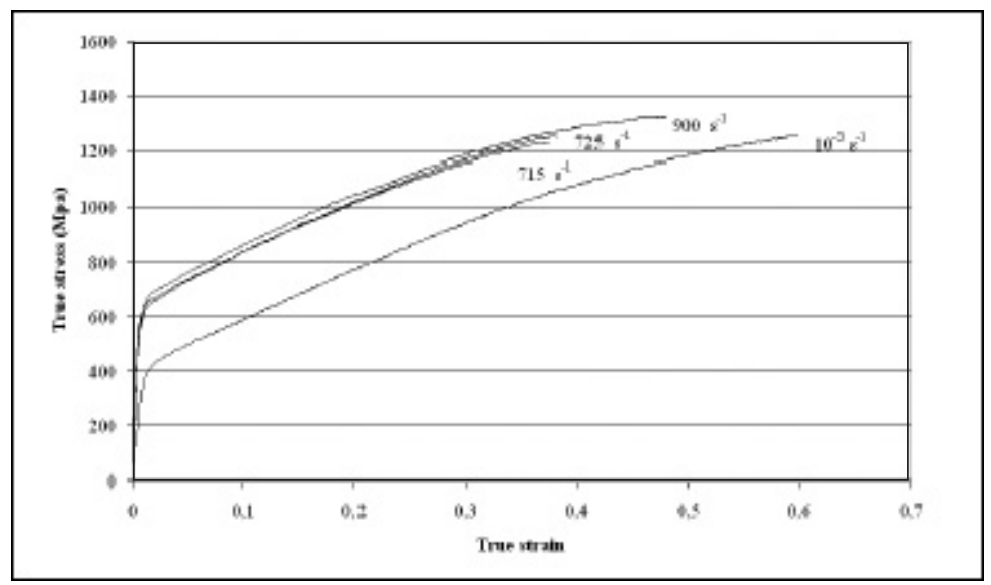

Figure 2. Stress versus strain for 304L stainless steel at various strain-rates. 


\subsection{Thermal tools}

The temperatures measurement used in this study should not be intrusive, so that it won't disturb the determination of mechanical behaviour of samples and it will possess a high acquisition frequency. Optical pyrometry measurement is the most adapted in this study. A pyrometer with thermal radiation allows collecting part of the emission of a body. It is a thermo sensitive element which absorbs part of the power emitted by the source and which transforms it into electric signal [6]. The apparatus for temperature measurement on figure 1 is made up with:

- An Cincinnati InSb multidetector (16 sensitive elements distributed in line of $43 \mu \mathrm{m}$ by $43 \mu \mathrm{m}$ ).

- Two parabolic mirrors used as focalisation system.

- Acquisition System Nicolet acquires at $1 \mathrm{MHz}$.

- A PC allowing the data acquisition.

The multidetector sweeps the parallelepipedic sample perpendicularly at bars axis. Contrary to the lenses, the parabolic mirrors do not induce any chromatic or geometrical aberration.

The measurement of the temperature requires that the emissivity of the material should be determined in the field wavelengths of the detector. The coefficient of emissivity represents the part of the radiation emitted by the material. Emissivities were measured under vacuum, in laboratories [7]. The total error made on the temperature is around $\pm 6 \%$, this error is mainly due to the determination of the emissivity.

\section{RESULTS}

\subsection{Mechanical behaviour measurement}

Tests carried out on Split Hopkinson Bar showed that 304L stainless steel and 5754 aluminium alloy are sensitive to strain-rate of loading. For both materials, the increasing strain-rate of loading generates an increasing of yield and flow stress (Figure 2 and Figure 3). However, the behaviour of both materials are different when strain-rate of loading increases. In the case of 304L stainless steel, yield and flow stress undergoes an important variation between a test realized in quasi-statics and another carried out in dynamic (Figure 2). On the contrary, the stress necessary to deform 5754 aluminium alloy, increases gradually with the strain-rate of loading (Figure 3). At last, we could notice that repetitivity of the test is excellent for both materials at the same strain-rates of loading.

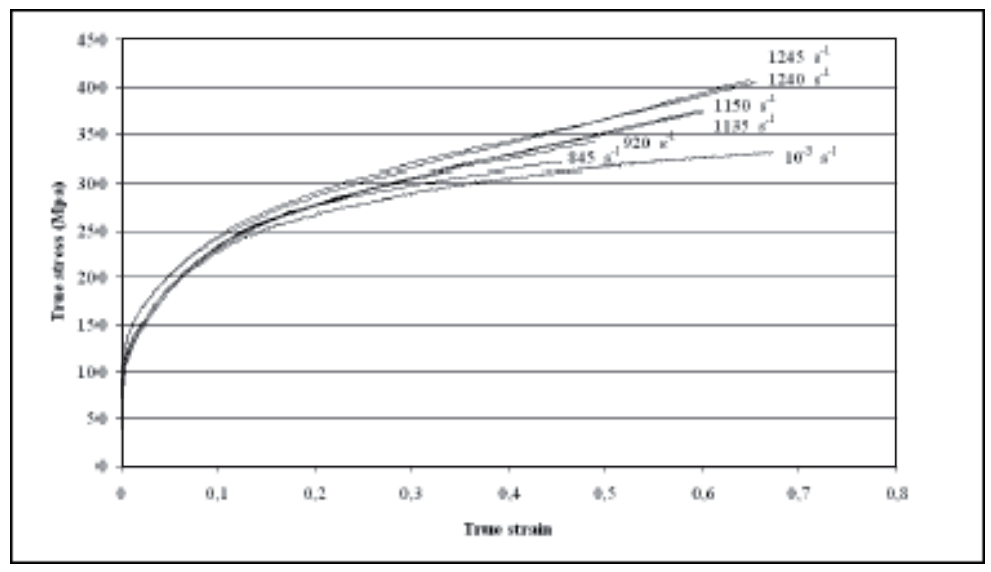

Figure 3. Stress versus strain for 5754 aluminium alloy at various strain rates. 


\subsection{Measurement of temperatures and computation of the Taylor-Quinney coefficient}

\subsubsection{Checking of the homogeneity of the temperatures and the deformations on Split Hopkinson Bar}

Results of the tests on figures 4 and 5 clearly show the homogeneity of the temperatures on the surface of the sample. No localization of the deformation appears.

The rise in temperature between aluminium alloy and steel are not very different for the same deformation. For a true strain of 0.5 , the increase in temperature is $110^{\circ} \mathrm{C}$ for $304 \mathrm{~L}$ stainless steel and $90^{\circ} \mathrm{C}$ for 5754 aluminium alloy. The greatest part of the deformation energy is transformed into heat.

\subsubsection{Effect on strain rate on temperatures}

The temperature increases in a constant way throughout the deformation for 304L stainless steel (Figure 6). On the contrary, the temperature curves for 5754 aluminium alloy are not linearly (Figure 6 and Figure 7). For both materials, the rise in temperature is independent from strain rate.

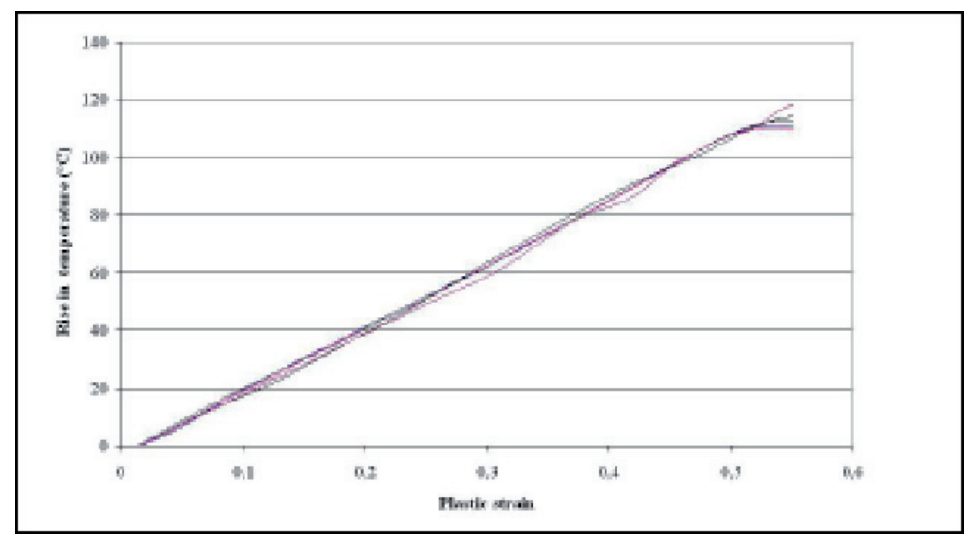

Figure 4. Rise in the temperature for $304 \mathrm{~L}$ stainless steel sample deformed at $1740 \mathrm{~s}-1$ for various detectors sweeping the whole of the bar.

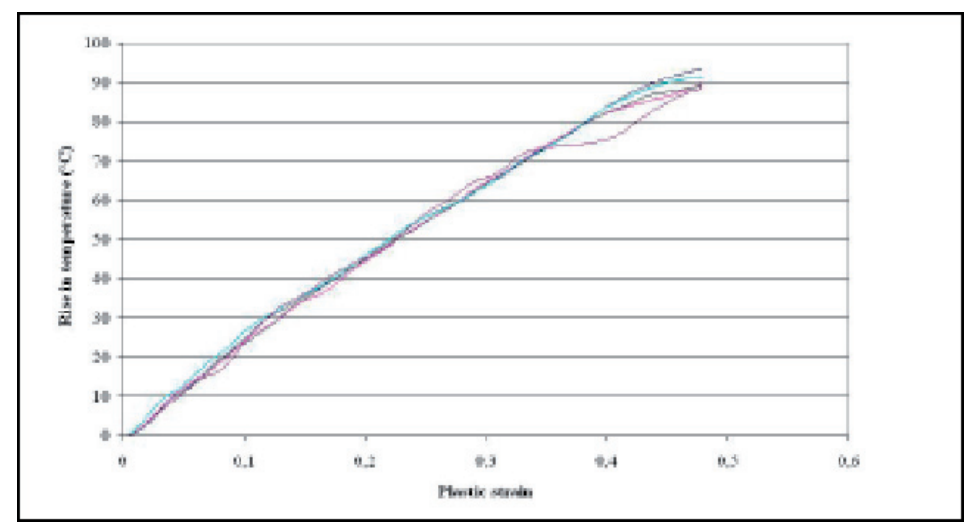

Figure 5. Rise in the temperature for 5754 aluminium alloy sample deformed at $1620 \mathrm{~s}-1$ for various detectors sweeping the whole of the bar. 


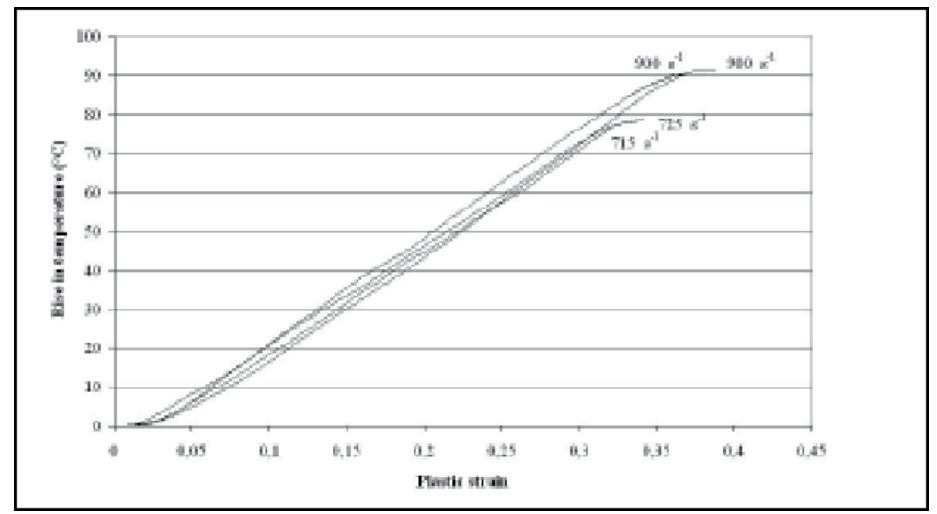

Figure 6. Rise in temperature for $304 \mathrm{~L}$ stainless steel at various strain rates.



Figure 7. Rise in temperature for 5754 aluminium alloy at various strain rates.

Whatever the strain-rate of loading, temperature increases linearly for 304L stainless steel and not for 5754 aluminium alloy. TEM studies could be necessary. Nevertheless, literature reported that this phenomenon is due to a reorganization of dislocations, which leads to a reduction in their density $[8,9,10,11]$.

\subsubsection{Calculation of the Taylor-Quinney coefficient}

The equation of heat in the case of the thermoplastic problem is written:

$$
\underbrace{\beta \sigma_{\mathrm{m}} \frac{\partial \varepsilon \mathrm{pl}}{\partial \mathrm{t}}}=\underbrace{\rho \mathrm{C}_{\mathrm{v}} \frac{\partial T}{\partial t}}
$$

Energy resulting from mechanical work Thermal energy

where : $\beta$ : Taylor-Quinney coefficient, $\sigma_{\mathrm{m}}$ : mean stress, $\varepsilon \mathrm{pl}:$ plastic strain, $\rho:$ density, $\mathrm{C}_{\mathrm{v}}:$ specific heat

$\beta$ coefficient corresponds with the plastic fraction of work converted into heat [12]. It is generally noted in literature as constant and typically ranged between 0.8 and 1. Values of the Taylor-Quinney coefficient quoted in literature tally with the calculation of this coefficient carried out in our test (Fig. 8).

However, the waves measured with the incident and transmitted bars fluctuate. The measuring accuracy at the beginning of loading is thus worse and does not allow determining precisely the flow stress of the material. It explains, values superiors to 1 for the Taylor-Quinney coefficient could be 




Figure 8. Evolution of Taylor-Quinney coefficient function of plastic strain for 304L stainless steel.

obtained for weak deformations. Results achieved at the beginning of loading cannot be interpreted.

\section{CONCLUSIONS}

The yield stress of 304L stainless steel significantly increases with the strain rate of loading. Strain hardening. Strain hardening increases gradually with strain rate for 5754 aluminium alloy. Both effects suggest that fast industrial dieing processes will not be easier than quasi-static ones. The increase of the yield stress with the strain rate can be related with the evolutions of the microstructures during the deformation process, in particular with the generation of dislocations, the increase of their number, with the strain their accumulation during compression, in the evolution of their morphological characteristics $[8,9,10,11]$. Temperatures generated during dynamics compression test have been measured for thin samples at high strain-rates. Those measurements allowed for the checking of the temperature homogeneity along the sample during the test. They show that assuming a homogeneous state of strains and stress in the sample tested with a SHPB is valid in the present case. For strains greater than $20 \%$, temperature measurements permit the calculation of Taylor-Quinney showing its decrease with the strain rate increases.

\section{References}

[1] N. Ranc: Etude des champs de température et de déformation dans les matériaux métalliques solicités à grandes vitesse de déformation. Thèse de Doctorat (2005). Université ParisX, Nanterre.

[2] V. Pina: Mesure de températue de bandes de cisaillement adiabatique dans les alliages de titane. Thèse de Doctorat (1997). Université ParisX, Nanterre.

[3] W.-S. Lee and C.-F. Lin: Effect of prestrain and strain rate on dynamic deformation characteristics of 304L stainless steel; part 2 - Microstructural study: Materials Science and Technology: August 2002, Vol. 18. 869

[4] J. Schiotz, T. Leffers, B.N. Singh: Modeling of dislocation generation and interaction during high-speed deformation of metals: Radiation Effect and Defects in Solids, 2002, Vol. 157, pp. 193-200

[5] G. Gary: Comportement des matériaux à grande vitesse de déformation. Modélisation. Techniques de l'ingénieur. Traité Génie Mécanique.

[6] F. Cabannes. Pyrométrie optique. Techniques de l'ingénieur. Traité Génie Mécanique.

[7] P. Hervé: Influence de l'état de surface sur le rayonnement thermique des matériaux solides. Thèse de Doctorat (1977). Université Paris VI. 
[8] W.-S. Lee and C.-F. Lin: Impact properties and microstructure evolution of 304L stainless steel: Materials Science and Technology: A308 (2001), pp. 124-135

[9] W.-S. Lee and C.-F. Lin: Effect of prestrain and strain rate on dynamic deformation characteristics of 304L stainless steel; part 1 - mechanical behaviour: Materials Science and Technology: August 2002, Vol. 18. 869

[10] T. Yuritzinn: Impact resistance of 304L type stainless steel plates: Identification of Lemaitre and Chaboche damage model's parameter at different strain rates. J. Phys. IV France 10 (2000)

[11] A. Roos, J.T.M. De Hosson, E. Van der Giessen: High speed dislocation in high strain-rate deformations: Computational materials Science, 20 (2000), pp. 19-27

[12] P. Rosakis, A. J. Rosakis, G. Ravichandran, J. Hodowany: On the partition of plastic work into heat and stored energy in metal; Part I and Part II: Report of California Institute of Technology (1998). 